\title{
Environmental radioactive monitoring of the CEA research centres in France: Overview and perspectives
}

\author{
M. Calvez and P. Fracas \\ French Alternative Energies and Atomic Energy Commission, Risk management unit, Nuclear \\ safety and protection division, Centre de Fontenay-aux-Roses, 18 route du panorama, \\ BP. 6, 92265 Fontenay-aux-Roses, France
}

\begin{abstract}
Environmental protection is a priority and a constant concern at CEA. Seven centres are subject to environmental radioactive monitoring, owing to their research activities entailing radioactive discharges. The continuous improvement approach helps to optimise these discharges and achieve negligible impact by these activities on the neighbouring populations and the environment. The environmental radioactivity levels are therefore very low and are indeed often undetectable using the most sophisticated measuring devices. These measures provide appropriate information regarding environmental monitoring. In addition, an evaluation of the dosimetric impact induced by CEA activities is carried out annually on each site and the highest levels recorded do not exceed one micro-sievert per year.
\end{abstract}

\section{HISTORICAL BACKGROUND}

\subsection{Location and activity of the centres}

CEA is a leader in research, development and innovation. It is a public body that was created in 1945 by General de Gaulle and comprises 10 centres, located in a number of regions. Its fields of research include radioactive substances. In the following seven CEA research centres, where radioactive discharges occur, all possible steps are taken to control the environmental impact of their activities:

- Cadarache: nuclear energy, controlled thermonuclear fusion, microbiology and new energy technologies;

- Fontenay-aux-Roses: nuclear facilities undergoing clean-out and decommissioning, life sciences and technologies;

- Grenoble: nuclear facilities undergoing clean-out and decommissioning, new technologies for energy, health, information and communication;

- Saclay: nuclear power plant safety, nuclear waste management, material and life sciences;

- Marcoule: uranium preparation techniques, reprocessing of spent nuclear fuels, nuclear facility clean-out and decommissioning techniques, and management of the most highly radioactive waste;

- Bruyères-le-Châtel and Valduc: operation and safety of French nuclear weapons.

\subsection{Management of radioactive effluent discharges}

\subsubsection{Origin of discharges}

Discharges come from research reactors, study laboratories, processing of effluent and nuclear facilities undergoing clean-out and decommissioning. All steps are taken to minimise them: collection of waste directly from the facilities and removal to appropriate disposal solutions, processing of effluents in appropriate facilities with recycling of water. 


\subsubsection{Regulation authorisations}

In France, as in all member States of the European Union, the regulations are based on the transposition into national legislation of the requirements of the Euratom treaty. The operation of a nuclear facility in particular requires the granting of a license for liquid or gaseous discharges, in order to guarantee the lowest possible radiological impact on man and the environment.

These requirements are set by independent safety regulators: the Autorité de sûreté nucléaire (ASN) for basic nuclear installations, and the Autorité de sûreté nucléaire défense (ASND) for defence-related nuclear facilities. Other facilities, such as liquid discharge plants, are covered by specific discharge requirements set by the préfet. The requirements also specify the framework for the measures to be taken by CEA to establish and implement an environmental monitoring program.

The licenses in force at CEA were issued from 1988 to 2010. The most recent ones adopted the principle of reducing the difference between the discharges authorised by the license and the actual discharges. This reduction can be by a factor of up to 100, as in Saclay for gaseous aerosol discharges.

\subsubsection{Radioactive discharges into water}

Radioactive effluents are stored in tanks according to their specific nature and activity level. They are then transferred to one of CEA's treatment plants. A large part of the radioactivity is recovered in the form of solid waste. Only the purified liquid residue, of which the radiological and physical-chemical properties are compatible with the licenses, can be discharged into the environment after numerous checks carried out before, during and after discharge.

Continuous improvement of the performance of the facilities and processes over the years has enabled these discharges to be minimised. They are all below the authorised limits.

\subsubsection{Radioactive discharges into air}

On leaving a nuclear facility, gaseous effluents are first of all filtered in order to minimise the emission of substances into the atmosphere. All discharge outlets are equipped with radioactivity monitoring systems. These discharges are below the authorised annual limits.

\subsubsection{Example of historical discharge trends}

The Saclay centre asked a CEA laboratory to analyse two trees more than 50 years old, in order to create a picture of its gaseous tritium discharges since 1954. Based on a detailed measurement of the organically bound tritium, it was possible to extrapolate the discharges prior to 1968, the year in which systematic monitoring was set up, using appropriate liquid scintillation counters. The tritium discharges resulting from the research conducted since 1959 are thus visible and are reasonably closely in line with the measurements taken since then.

\section{ENVIRONMENTAL MONITORING}

\subsection{Monitoring objectives}

The discharge checks are supplemented by monitoring of the various compartments of the environment around the nuclear facilities, i.e. water, air, plants, soil and the components of the food chain. The monitoring program is regularly updated and tailored to the nature of the activities being carried out and the local characteristics of the environment. This system ensures that the provisions implemented by the facilities are effective. 


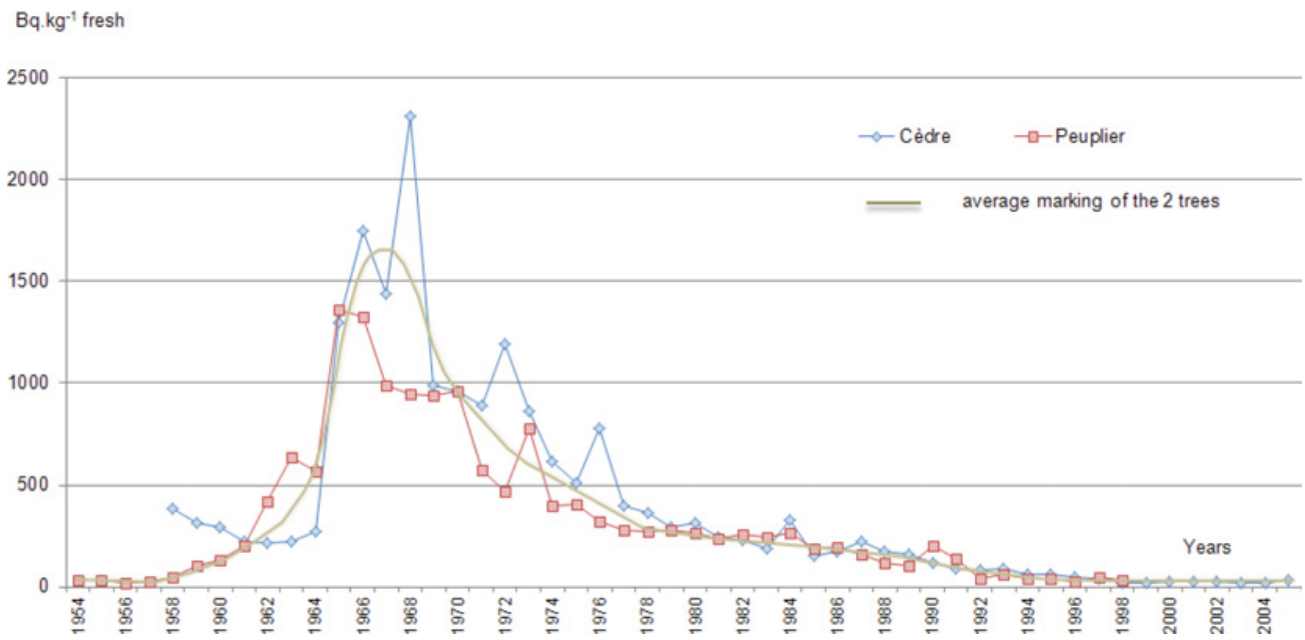

Figure 1. Organic tritium concentration in Saclay tree growth rings.

The responsibility for environmental monitoring inside and locally outside the sites lies with CEA. Sampling, with the samples then being analysed mainly by CEA laboratories, covers the main transfer routes: air, water, soil, fauna, flora and the products of the food chain.

Environmental monitoring traditionally comprises three functions:

- A routine monitoring function. These routine measurements are taken in the site's environment in order to obtain a permanent reference datum, for use as a benchmark against which the measurements taken in the case of a radiological event can be compared;

- An alert function, in the event of an abnormal rise in the level of radioactivity, via a network of permanent monitoring stations with real-time monitors of water and air quality in the centres and their immediate environment;

- A function for studying and understanding the working of the local environment, so that changes in radioactivity in the various compartments can be monitored over time and spatially.

\subsection{Resources dedicated to environmental monitoring}

Nearly 100 specialists are responsible for monitoring, measuring and interpreting the impact of facility operation. Every year, this monitoring involves tens of thousands of radiological analyses by the centres' specialised laboratories.

The validity of these measurements is backed up by numerous controls: environmental radioactive measurement approvals issued by ASN, COFRAC ${ }^{1}$ accreditation according to standard NF EN ISO/CEI $17025^{2}$, periodic comparison with the measurements taken by other laboratories, plus occasional counter-appraisals conducted by outside laboratories, confirming the results.

Since early 2009, like all other nuclear licensees, CEA has been required to use an approved laboratory for the measurements required by the regulations and to transmit its results to the national environmental radioactivity monitoring network. CEA's six laboratories currently hold 166 approvals for all environmental matrices. Owing to the drop in its nuclear activities, responsibility for the monitoring of CEA Grenoble was transferred in late 2009 to the nearby Laue-Langevin Institute, along with its approvals.

1 French accreditation committee.

2 concerning general requirements relative to the competence of calibration and testing laboratories. 
Table 1. Main environmental analysis decision thresholds (DT).

\begin{tabular}{|c|c|c|c|c|c|c|c|}
\hline Matrices & $\begin{array}{l}\text { Unit } \\
\text { Unit }\end{array}$ & $\begin{array}{c}\text { Total } \\
\text { alpha DT }\end{array}$ & $\begin{array}{c}\text { Total } \\
\text { beta DT }\end{array}$ & \begin{tabular}{|c|} 
Gamma \\
spectrometry \\
DT $\left(\right.$ eq. $\left.{ }^{137} \mathrm{Cs}\right)$
\end{tabular} & $\begin{array}{l}\text { Iodine } \\
131 \text { DT }\end{array}$ & $\begin{array}{c}\text { Tritium } \\
\text { DT }\end{array}$ & $\begin{array}{l}\text { Carbon } \\
14 \mathrm{DT}\end{array}$ \\
\hline $\begin{array}{l}\text { Atmospheric } \\
\text { aerosols }\end{array}$ & $\mathrm{Bq} / \mathrm{m}^{3}$ & $\begin{array}{l}2 \times 10^{-5} \text { to } \\
3.6 \times 10^{-4}\end{array}$ & $\begin{array}{c}3 \times 10^{-5} \text { to } \\
3 \times 10^{-4}\end{array}$ & $\begin{array}{c}5 \times 10^{-7} \text { to } \\
10^{-5}\end{array}$ & - & - & - \\
\hline Air & $\mathrm{Bq} / \mathrm{m}^{3}$ & - & - & - & $\begin{array}{l}7.5 \times 10^{-4} \\
\text { to } 5 \times 10^{-4}\end{array}$ & $\begin{array}{c}10^{-1} \text { to } \\
3 \times 10^{-1}\end{array}$ & $\begin{array}{l}2.5 \times 10^{-3} \\
\text { to } 4 \times 10^{-1}\end{array}$ \\
\hline Plants & $\begin{array}{l}\mathrm{Bq} / \mathrm{kg} \\
\text { fresh }\end{array}$ & - & $\begin{array}{l}1.75 \text { to } \\
5 \times 10^{1}\end{array}$ & $\begin{array}{c}1.2 \times 10^{-1} \\
\text { to } 3\end{array}$ & - & $\begin{array}{l}1 \text { to } 10^{1} \\
\left(\text { free }{ }^{3} \mathrm{H}\right)\end{array}$ & - \\
\hline Milk & $\mathrm{Bq} / \mathrm{l}$ & - & $\begin{array}{c}3 \times 10^{-1} \text { to } \\
6 \times 10^{-1}\end{array}$ & $\begin{array}{c}1 \times 10^{-1} \text { to } \\
4 \times 10^{-1}\end{array}$ & - & $\begin{array}{c}1 \text { to } 5 \\
\left(\text { free }{ }^{3} \mathrm{H}\right)\end{array}$ & - \\
\hline Soil & $\begin{array}{c}\mathrm{Bq} / \mathrm{kg} \\
\text { dry }\end{array}$ & - & $\begin{array}{c}10^{1} \text { to } \\
5 \times 10^{1}\end{array}$ & $\begin{array}{c}2 \times 10^{-1} \\
10^{1}\end{array}$ & - & - & - \\
\hline Water & $\mathrm{Bq} / \mathrm{l}$ & $\begin{array}{c}2 \times 10^{-2} \text { to } \\
8 \times 10^{-2}\end{array}$ & $\begin{array}{c}3.5 \times 10^{-2} \text { to } \\
1.5 \times 10^{-1}\end{array}$ & $\begin{array}{c}7.5 \times 10^{-3} \text { to } \\
5 \times 10^{-1}\end{array}$ & - & 2.5 to 6 & $\begin{array}{c}5 \times 10^{-3} \\
\text { to } 4\end{array}$ \\
\hline
\end{tabular}

This approval process has led to harmonisation of practices, guaranteeing a minimum level of requirements both for sampling and for analysis. Under the supervision of CEA, France's five main nuclear licensees (ANDRA, AREVA, CEA, EDF and the French Navy (Marine nationale)) are preparing a series of methodology guides for water, air and bio-indicator sampling practices.

The main decision thresholds (DT) reached by the CEA laboratories are detailed below according to the environmental compartment and the main types of routine analyses carried out. Measurement sensitivity may vary from one centre to another.

\section{CONTENTS OF REGULATION ENVIRONMENTAL MONITORING}

\subsection{Atmospheric environment}

\subsubsection{Atmospheric monitoring stations}

Atmospheric monitoring usually involves fixed monitoring stations located around the periphery of the sites, at a distance generally between $250 \mathrm{~m}$ and several $\mathrm{km}$ from the gaseous discharge outlets. At least three to four stations are situated around each site, one of which is positioned under the prevailing winds.

The measurements, the condition of the sensors and the meteorological data are entered in real-time on the centre's environmental monitoring table. These data are input into computers offering a real-time display, an alarm system and archival of all the data. Continuous samples are taken for off-line analysis.

\subsubsection{Dry atmospheric fall-out}

3.1.2.1 Atmospheric aerosols. At all the centres, aerosols are continuously sampled by filters, using an air pumping device a few meters above the ground. The filters on the automated stations are in principle changed daily.

The aerosol activity is measured after decay of the natural radioactivity of the short-lived daughter products of radon. The analyses are conducted using proportional counters allowing simultaneous measurement of the total $\alpha$ activity (in equivalent ${ }^{239} \mathrm{Pu}$ ) and the total $\beta$ activity (in equivalent ${ }^{90} \mathrm{Sr} /{ }^{90} \mathrm{Y}$ ). The residual $\alpha$ activity of these aerosols is less than $0.1 \mathrm{mBq} / \mathrm{m}^{3}$ and the $\beta$ activity is on average between $0.3 \mathrm{mBq} / \mathrm{m}^{3}$ and $0.7 \mathrm{mBq} / \mathrm{m}^{3}$. The radioactivity of the dust in suspension in the air is due mainly to naturally occurring radionuclides, their daughter products attached to the aerosols and radon. The values 
fluctuate according to variations in the level of dust in the air, but remain relatively stable from one year to another.

3.1.2.2 Halogens. Five centres monitor halogens, more particularly iodine 131, by continuous trapping on activated carbon cartridges, which are collected on a weekly basis. Off-line measurement uses gamma spectrometry.

3.1.2.3 Carbon 14. Carbon 14 is monitored by two centres using continuous trapping (soda solution) in chilled bubblers. Monthly measurement is carried out using liquid scintillation.

3.1.2.4 Tritium. Tritium is monitored by all the centres using continuous trapping (demineralised water solution), in chilled bubblers. The tritium activity in the water in the bubblers is counted every week by liquid scintillation.

\subsubsection{Exposure to ambient radiation}

Dosimeters are used to measure the ambient gamma radiation. This reflects the external exposure to natural gamma radiation, the intensity of which varies with the geological component and the geographical location. Artificial exposure arising from the nuclear facilities in normal operation is usually low.

The external irradiation monitoring devices are installed on the fences around each centre and in the atmospheric monitoring stations. They are of two types: ionisation chamber for continuous, realtime measurement of gamma emitter radioactivity in the air, or radiophotoluminescent dosimeter for the integrated dose during the exposure period. The values are approximately 65 to $100 \mathrm{nGy} / \mathrm{h}$ in the vicinity of the CEA centres.

\subsubsection{Mobile intervention and monitoring resources}

The fixed installations are supplemented by vehicles intended for routine monitoring or for intervention in the event of a radioactive incident or accident. These mobile laboratories comprise a number of environmental radioactivity $(\alpha / \beta$ analyses, $\gamma$ spectrometry and/or irradiation) and meteorological measuring devices.

\subsection{Terrestrial environment}

\subsubsection{Grasses and crops}

Plant-life is the subject of specific monitoring, because it is one of the routes for transfer to man, directly through ingestion of food or indirectly through the ingestion of animal products. Plants are also biological contamination indicators.

Grass samples are collected monthly from around the atmospheric monitoring stations. Vegetables and fruit from nearby farms are periodically analysed. The analyses comprise gamma, and alpha spectrometry, total counting and/or liquid scintillation (free and/or bound ${ }^{3} \mathrm{H}$ and ${ }^{14} \mathrm{C}$ ). The natural radioactivity of plants is primarily due to the ${ }^{40} \mathrm{~K}$ and ${ }^{7} \mathrm{Be}$ originating in the upper atmosphere. Tritium is present in the grass near the sites from which gaseous discharges are the highest.

\subsubsection{Milk}

Owing to its own potassium content, milk is a naturally radioactive product. The contribution of gaseous discharges to tritium activity in milk is detected only at trace levels and extremely locally. 
The milk comes from farms situated within a radius of less than $10 \mathrm{~km}$ around each site and, whenever possible, under the prevailing winds. In an urban environment, this monitoring is impossible. The main purpose of the checks carried out at least every month, is to look for radionuclides discharged by the facilities, such as tritium and radionuclides of importance for radiation protection, such as radioisotopes of caesium or iodine, or even ${ }^{90} \mathrm{Sr}$.

\subsubsection{Soil}

The topsoil is sampled every year at one or more sampling points on the five centres, because it is representative of the ground level deposits. Gamma, alpha spectrometry and/or total counting are carried out. The radioactivity detected is primarily of natural origin.

\subsection{Continental aquatic environment}

\subsubsection{Water}

Water is sampled from the hydrographic network, from rivers, streams, ditches, lakes or ponds, referred to as surface water, located upstream and downstream of the effluent discharge point, as well as from the groundwater. This monitoring also includes rainwater.

The sampling frequencies vary from weekly for the receiving environments into which liquid effluents are discharged and monthly, or even quarterly, for remote surface water or water which does not interconnect with the receiving environment. The choice of groundwater monitoring points is determined by the topography of the site, the complexity of the hydrogeological network and according to the potential uses of the groundwater for drinking water or for crop irrigation. The analyses concern measurement of the total $\alpha$ and/or $\beta$ activity, $\gamma$ emitters, ${ }^{90} \mathrm{Sr},{ }^{14} \mathrm{C}$ and/or tritium.

\subsubsection{Sediments}

Sediment from the receiving environment (watercourses, ponds or sewerage networks) is sampled for each centre having a liquid effluent discharge license. The number of sampling points (up to 6) and the frequency (at least monthly) are tailored to the local conditions. The analyses concern measurement of the total $\alpha$ and/or $\beta$ activity, the $\gamma$ emitters, ${ }^{90} \mathrm{Sr},{ }^{14} \mathrm{C}$, tritium and/or $\alpha$ emitters.

\subsubsection{Aquatic fauna and flora}

Fish, phanerogams and reeds are collected monthly or annually at two sampling points in the watercourses in the vicinity of the discharge outlets. The analyses concern measurement of the total $\alpha$ and/or $\beta$ activity, the $\gamma$ emitters, ${ }^{90} \mathrm{Sr},{ }^{14} \mathrm{C}$, tritium and/or $\alpha$ emitters.

\section{EVALUATION OF THE DOSIMETRIC IMPACT}

The dosimetric impact of the activities is evaluated annually in each centre. Although based on conservative hypotheses, it is extremely low by comparison with the regulation annual dose limit for the public ( $1 \mathrm{mSv} / \mathrm{year})$ and reaches a maximum of about one micro-sievert per year.

This evaluation is based on numerical models validated using the actual annual discharges from the centres. The results of the environmental sample analyses reveal artificial radioactivity traces that are too small to be useful for dose estimation.

Transfers between the source of these discharges and the environment (water, air, vegetables, fruit, milk, etc.) are evaluated using dispersion models (liquid and atmospheric) taking account of the different types of radiation. The radiological consequences for man take account of the external (ambient radioactivity) and internal (inhalation and ingestion) contamination routes. The reference 
groups identified are homogeneous groups of individuals defined on the basis of realistic scenarios, according to the lifestyle and food habits of the neighbouring populations and the distance from the point of discharge.

\section{TRANSPARENCY AND ENVIRONMENTAL INFORMATION}

Ever since the French National Network for the Measurement of Environmental Radioactivity was set up, CEA has been a major contributor, sending in more than 70,000 results, or about $20 \%$ of the available data. This database, unique within Europe, centralizes information on environmental radioactivity and provides access to all the results at a national level (www.mesure-radioactivite.fr). The network relies on the assistance of laboratories approved by ASN, which have proven competence, a robust quality organisation and which have satisfactorily undergone inter-comparison testing.

CEA plays an active part in the National Network for the Measurement of Environmental Radioactivity, created in 2003. The centres have in particular acquired tools for managing and transmitting existing data to the website opened to the public in early 2010, giving access to the monitoring results of all the laboratories approved by ASN.

Around its centres, CEA ensures that the monitoring results concerning its sites are extensively distributed through periodic publications or information meetings with the local information committees set up for civil and defence-related nuclear facilities.

\section{CONCLUSIONS AND OUTLOOK}

In 2010, with regard to environmental monitoring around the seven centres concerned, CEA carried out 36,000 measurements required by the regulations, plus additional measurements for detailed characterisation of the possible impacts of the discharges. All of these measurements are clear evidence of the scale of the environmental monitoring work carried out and confirm that these radioactive effluent discharges have no impact on man and the environment.

Involving the laboratories in metrology and sampling is a means of reinforcing the stringency of the organisations and the quality of the measurements taken. The level of performance reached and the number of measurements now taken are compatible with the CEA sites' monitoring needs. To ensure that these results are more comprehensible, their presentation must be improved so that they are more informative.

The authority is giving thought to the monitoring strategy to be applied nationwide in the coming years. Along with the other nuclear stakeholders, CEA is taking part in this work and hopes that it will lead to optimised monitoring of its sites. The main regulatory texts which govern this monitoring are also currently under revision. 